\title{
Palliative care and neurology
}

\section{Time for a paradigm shift}

(0) 메]

Isabel Boersma, MS

Janis Miyasaki, MEd,

FRCPC, MD

Jean Kutner, MD, MSPH

Benzi Kluger, MD, MS

Correspondence to

Dr. Kluger:

benzi.kluger@ucdenver.edu
Supplemental data at Neurology.org

\section{ABSTRACT}

Palliative care is an approach to the care of patients and families facing progressive and chronic illnesses that focuses on the relief of suffering due to physical symptoms, psychosocial issues, and spiritual distress. As neurologists care for patients with chronic, progressive, life-limiting, and disabling conditions, it is important that they understand and learn to apply the principles of palliative medicine. In this article, we aim to provide a practical starting point in palliative medicine for neurologists by answering the following questions: (1) What is palliative care and what is hospice care? (2) What are the palliative care needs of neurology patients? (3) Do neurology patients have unique palliative care needs? and (4) How can palliative care be integrated into neurology practice? We cover several fundamental palliative care skills relevant to neurologists, including communication of bad news, symptom assessment and management, advance care planning, caregiver assessment, and appropriate referral to hospice and other palliative care services. We conclude by suggesting areas for future educational efforts and research. Neurology ${ }^{\circledR}$ 2014;83:561-567

\section{GLOSSARY}

MS = multiple sclerosis; PD = Parkinson disease.

In a 1996 review, the American Academy of Neurology Ethics and Humanities Subcommittee stated: "Many patients with neurologic disease die after long illnesses during which a neurologist acts as the principal or consulting physician. Therefore, it is imperative that neurologists under-

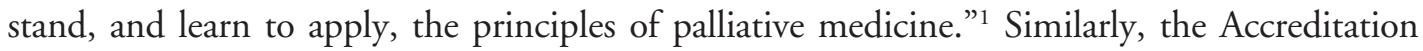
Council for Graduate Medical Education requires neurology residents to receive instruction in end-of-life and palliative care. ${ }^{2}$ However, research suggests that there are major gaps in the education of neurology resident physicians in these topics and low levels among neurologists of referrals for palliative care services. ${ }^{3,4}$ While palliative care emerged in the treatment of patients with terminal cancer, more recent developments in this field suggest that palliative care may be appropriate for any patient living with advanced, progressive illness or multiple comorbidities. As examples, palliative care been successfully applied to chronic illnesses such as heart failure, ${ }^{5}$ chronic pulmonary disease, ${ }^{6}$ and end-stage renal disease. ${ }^{7}$ There is also an emerging interest, in both research and clinical care, to apply these principles in neurology. ${ }^{8-10}$ Our goal in this article is to provide a starting point for neurologists to become more knowledgeable and comfortable with the principles of palliative medicine.

WHAT IS PALLIATIVE CARE AND WHAT IS HOSPICE CARE? Many health care professionals, including neurologists, hold misconceptions about palliative care. ${ }^{11}$ The most common misconception is that palliative care is synonymous with hospice. The lack of clarity regarding the similarities and differences between palliative care and hospice likely influences the view that only patients nearing the end of life are suitable candidates for palliative care. ${ }^{12}$ Similarly, some health care professionals believe palliative care is "giving up on patients" or "no care"; however, research efforts suggest that early palliative care interventions may positively affect both quality of life and survival..$^{13}$ Notably, palliative care can be used alongside curative treatments. ${ }^{14-16}$

From the Departments of Neurology and Psychiatry (I.B., B.K.) and Internal Medicine (J.K.), University of Colorado Anschutz Medical Campus, Aurora; and Department of Neurology (J.M.), University of Alberta, Edmonton, Canada.

Go to Neurology.org for full disclosures. Funding information and disclosures deemed relevant by the authors, if any, are provided at the end of the article. 
Dementia

Stroke or coma

Other neurologic disease including ALS, PD, MD, MG, or MS

Generic criteria
1. Stage $7 C$ or higher on the FAST scale ${ }^{e 19}$ AND

2. One or more of the following in the past year: aspiration pneumonia, pyelonephritis, septicemia, stage 3 or 4 pressure ulcers, recurrent fevers, other conditions suggesting limited prognosis, or inability to maintain sufficient fluid/caloric intake in past 6 months $(10 \%$ weight loss or albumin $<2.5 \mathrm{~g} / \mathrm{dL})$

1. Palliative Performance Scale ${ }^{e 20}$ score $\leq 40 \%$ AND

2. Poor nutritional status with inability to maintain sufficient fluid/caloric intake $(10 \%$ weight loss in 6 months, $7.5 \%$ weight loss in 3 months, serum albumin $\leq 2.5 \mathrm{~g} / \mathrm{dL}$, or pulmonary aspiration resistant to speech therapy interventions)

1. Critically impaired breathing including dyspnea at rest, vital capacity $<30 \%, \mathrm{O}_{2}$ need at rest, AND refusal of artificial ventilation, OR

2. Rapid disease progression (to bed-bound status, unintelligible speech, need for pureed diet, and/or major assistance needed for ADLs) with either:

A. Critical nutrition impairment in the prior year (inability to maintain sufficient fluid/caloric intake, continuing weight loss, dehydration, AND refusal of artificial feeding methods) OR

B. Life-threatening complications in the prior year (recurrent aspiration pneumonia, pyelonephritis, sepsis, recurrent fever, OR stage 3 or 4 pressure ulcers)

1. Terminal condition (can be multiple conditions) AND

2. Rapid decline over past 3-6 months as evidenced by progression of disease signs, symptoms and test results, decline in PPS $\leq 40 \%$, and involuntary weight loss $>10 \%$, and/or albumin $<2.5 \mathrm{~g} / \mathrm{dL}$

Abbreviations: $A D L=$ activities of daily living; ALS = amyotrophic lateral sclerosis; FAST = Functional Assessment Staging Test; MD = muscular dystrophy; $M G=$ myasthenia gravis; MS = multiple sclerosis; PD = Parkinson disease; PPS = Palliative Performance Scale.

The Center to Advance Palliative Care defines palliative care as "specialized medical care for people with serious illnesses. This type of care is focused on providing patients with relief from the symptoms, pain, and stress of a serious illness - whatever the diagnosis. The goal is to improve quality of life for both the patient and the family. Palliative care is provided by a team of doctors, nurses, and other specialists who work with a patient's other doctors to provide an extra layer of support. Palliative care is appropriate at any age and at any stage in a serious illness, and can be provided together with curative treatment." ${ }^{17}$ Notably, palliative care may be applicable early in the course of illness, including the time of diagnosis, to help the patient adjust to the many changes in their life and life plans. ${ }^{18,19}$ Similarly, palliative care may complement life-prolonging therapies, such as chemotherapy or radiation therapy, and investigations needed to better understand and manage distressing clinical complications. ${ }^{15}$

Palliative care describes an approach to patient care available from the time of diagnosis through bereavement and may be delivered in conjunction with standard care or through specialized services including hospice care, inpatient palliative care, outpatient palliative care clinics, and home palliative care. Hospice care refers specifically to palliative care for the end of life. In the United States, the Medicare hospice benefit is available to patients certified by 2 physicians to have a prognosis of 6 months or less if their disease runs its natural course and who have chosen directly or through surrogates to focus medical care on comfort. ${ }^{20,21} \mathrm{It}$ is offered when disease-directed treatments are no longer wanted or beneficial. The table provides hospice eligibility guidelines for specific neurologic conditions. However, it should be noted that patients with poor prognoses may be eligible for hospice without meeting these specific guidelines.

The palliative care approach augments traditional care for neurology patients in several ways. While traditional approaches emphasize the preservation of function and prolongation of life, palliative care draws additional attention to the relief of suffering and places importance on planning for decline and death as an expected and natural outcome rather than as a failure of medical treatment. ${ }^{22}$ Palliative care transcends the historical patient-physician dyad by addressing caregiver strain and offering supportive services to family members such as respite care and counseling. ${ }^{22,23}$ Finally, palliative care assesses and treats medical, psychosocial, and spiritual issues including not only pathologic diagnoses but other sources of distress, including normal reactions to living with a life-threatening, progressive, and/or disabling illness.

WHAT ARE THE PALLIATIVE CARE NEEDS OF NEUROLOGY PATIENTS? This question can be broken down into related questions: Would neurology patients and family members benefit from palliative services? Are neurology patients receiving adequate care in these areas? On the basis of both questions, we believe there is a substantial and growing need for neurologists to apply the principles of palliative medicine to the care of patients with progressive, chronic illnesses. ${ }^{1,9}$ Regarding the question of benefit, neurologic diseases are largely incurable, reduce life expectancy, ${ }^{24}$ and are associated with pain, depression, and other symptoms that are difficult to control. ${ }^{25}$ 
Miyasaki et al. ${ }^{26}$ showed that symptom burden in advanced Parkinson disease (PD) is similar to that in metastatic cancer. Caregivers of neurology patients also have similar, if not higher, rates of distress and burnout as caregivers of patients with cancer. ${ }^{27}$

Regarding the question of adequacy of current palliative services, place of death and documentation of advance directives offer objective measures of physician performance. Hospital deaths among patients with chronic neurologic disorders are high: 43\% for $\mathrm{PD}$ and $56 \%$ for multiple sclerosis (MS). ${ }^{28}$ However, hospice deaths are extremely uncommon in PD and MS: $0.6 \%$ and $2.5 \%$, respectively. ${ }^{28}$ Only $9 \%$ of patients with idiopathic PD die in their own home compared with $17 \%$ of the general elderly population. ${ }^{29}$ These are striking statistics because research overwhelmingly indicates that the majority of patients prefer to die at home. ${ }^{30}$ Furthermore, although neurologists broach advance care planning late in the disease course if at all, patient surveys suggest that at least $50 \%$ of patients with PD want to discuss advance care documents with their physician early in their disease course. ${ }^{31}$ Even in patients with advanced dementia, less than $20 \%$ have advanced directives documented. ${ }^{32,33}$ Regarding symptom management, multiple studies show that neurologists frequently fail to adequately assess and treat many symptoms associated with quality of life including depression, fatigue, pain, and sleep. ${ }^{34-36}$

DO NEUROLOGY PATIENTS HAVE UNIQUE PALLIATIVE CARE NEEDS? We propose that traditional models of palliative care do not sufficiently address the unique needs of patients and family members living with a neurologic diagnosis. Moreover, palliative physicians who are largely trained in internal medicine may have less comfort with neurologic illness than cancer or other medicine diagnoses. ${ }^{37}$ Patients with a life-limiting neurologic illness often have a long and variable disease progression punctuated by cognitive impairment, behavioral issues, and communication problems, in addition to motor symptoms. ${ }^{38}$ This trajectory differs from the sharp decline seen in many patients with cancer. ${ }^{39}$ Fortunately, palliative care services are increasingly recognizing the needs of noncancer patients, particularly in rapidly progressing neurologic conditions such as motor neuron disease. ${ }^{38}$

Differences between neurology and other patients include symptom profiles, psychosocial issues, caregiver needs, and effects on spiritual well-being. As examples, patients with motor neuron disease experience more demoralization, hopelessness, and suicidal ideation than patients with metastatic cancer $^{40}$; patients with brain cancer have distinct symptom profiles including more cognitive problems, seizures, and communication deficits than patients living with other types of cancers ${ }^{41}$; and patients with Huntington disease have distinctive social work needs as the result of combined behavioral, psychiatric, movement, and cognitive issues. ${ }^{42}$ Notably, young patients with Huntington disease can be particularly challenging to place in nursing homes, and social workers experienced in caring for these patients are necessary to provide the highest quality of care. ${ }^{43}$ In our clinical experience regarding spiritual well-being, neurology patients experience their disease as something intrinsic to their person, which clearly differs from patients with cancer who see "the cancer" as something outside of themselves. The physical and cognitive disabilities associated with neurologic illness also contribute to feelings of being "useless" or a "burden" and may contribute to higher rates of demoralization. ${ }^{40}$ Neurologic diseases are associated with caregiver distress and reduced quality of life related to caregiving, ${ }^{44}$ well-being, depression, and demoralization. ${ }^{45,46}$ Caregivers of patients with dementia are more adversely affected by their role, have unique psychological issues compared with cancer caregivers (e.g., losing parts of their spouse one day at a time, delusions of infidelity), ${ }^{47}$ and are at high risk of complicated bereavement. ${ }^{48}$

WHAT PALLIATIVE CARE SKILLS DO NEUROLOGISTS NEED? All physicians, including neurologists, should have familiarity and comfort with several fundamental palliative care skills including communicating bad news, nonmotor symptom assessment and management, advance care planning, and caregiver assessment. For more complex or advanced patients, referral to palliative care specialty teams may be appropriate, including inpatient palliative care consultation, outpatient palliative care clinics, home palliative care, or hospice.

COMMUNICATION AT THE TIME OF DIAGNOSIS Data from patients with heart failure have shown that palliative care should start at the time of diagnosis, ${ }^{49}$ yet research suggests that physician communication is often inadequate or ineffective, particularly for new diagnoses. ${ }^{50,51}$ This impression was reinforced at a round-table discussion at a continuing medical education event where patients with PD and caregivers discussed their experience of being diagnosed, including not having enough time for questions, not understanding what their diagnosis actually meant, not knowing where to go for support, and feeling abandoned by their doctor after being given bad news.

Regarding ways to communicate bad news, there are a number of tools physicians can utilize including SPIKES (Setting up the interview, assessing patient's Perception, obtaining patient's Invitation, giving 
Knowledge, address Emotions, Strategy and Summary $)^{52}$ or the Vital Talk Web site and smartphone application. ${ }^{53}$ When delivering a serious diagnosis, physicians must bring their full attention to the patient and figure out what they know about the diagnosis. Obtaining an invitation before sharing sensitive information such as prognosis and other potentially distressing information refers to finding out how much the patient wants to know and is especially important in the initial interview. Using open-ended questions and assessing emotions and feelings are critical to optimally support the patient. It is crucial that neurologists finalize the meeting with a follow-up including what to do when the patient has had a chance to process the information and now has more specific questions. This practice is particularly helpful to support the patient and minimize feelings of abandonment. ${ }^{52}$

SYMPTOM ASSESSMENT AND MANAGEMENT Neurologists need to carefully assess and treat nonmotor symptoms such as pain, depression, anxiety, fatigue, sleep, constipation, urinary urgency, and sexual dysfunction. Multiple studies in several populations have shown that nonmotor symptoms over time are among the most function-limiting for patients, and affect caregiver burden and overall quality of life more than motor symptoms. ${ }^{54-56}$ The management of these debilitating symptoms depends on their recognition by physicians. ${ }^{57}$ Research suggests that as many as $50 \%$ of patients with PD who have depression are not treated, despite evidence that treatment parallels that of the general population (e.g., selective serotonin reuptake inhibitors for depression and anxiety). ${ }^{58,59}$ Some issues may not be readily treatable, but should still be closely followed (e.g., dementia, dysphagia, and weight loss/nutritional status) because they may require additional support or affect advance care planning.

ADVANCE CARE PLANNING All neurologists should be knowledgeable about and feel comfortable discussing advance care planning with their patients while the patient is cognitively able. Many patients have never heard of advance care planning, and $30 \%$ of patients with advance care plans do not share these with their physicians. ${ }^{60}$ Contrary to the common clinical perception that patients do not want to discuss advance directives, patients often cite their expectation for physicians to initiate this discussion when asked about barriers to planning for the future, and patients who engage in end-of-life conversations with their doctors report greater satisfaction with their care. ${ }^{\mathrm{el}, \mathrm{e} 2}$ Notably, having conversations about death and dying with patients lowers the risk of aggressive treatment at the end of life. ${ }^{\mathrm{e} 2}$ Advance care planning includes topics such as medical durable power of attorney, financial power of attorney, living will, and cardiopulmonary resuscitation directive. Physicians may also want to less formally discuss overall goals of care including understanding important life goals and patient and caregiver fears. Health care professionals who care for neurology patients should have regionspecific information regarding these topics readily available for patients and keep an updated copy of completed forms with patient records. Patients should also be informed to keep these documents on their refrigerator and distribute copies to family members.

CAREGIVER ASSESSMENT Caregivers are at risk of chronic illness, ${ }^{\mathrm{e} 3}$ impaired sleep, ${ }^{\mathrm{e} 4}$ depression, ${ }^{\mathrm{e}}{ }^{5}$ and cardiovascular disease, ${ }^{\mathrm{e}, \mathrm{e} 7}$ and can have up to a $60 \%$ increased mortality rate compared with agematched controls that are not caregivers. ${ }^{\text {es }}$ The increase in caregiver mortality rates is related to both providing care and strain, ${ }^{\mathrm{e}}$ which in caregivers of patients with PD, has been shown to increase with disease progression. ${ }^{e 9}$ It has also been shown that caregivers of patients residing in nursing homes and caregivers who are well supported and do not report feeling distress have lower mortality rates.$^{\mathrm{e} 8}$ Caregiver quality of life is also associated with patient quality of life-thus, when patients spend their last months of life in the intensive care unit or die a traumatic death, it affects caregivers. ${ }^{\text {e10 }}$

Caregiver support from neurologists begins by adequately assessing their needs. The very act of asking caregivers how they are doing is often met with gratitude and may relieve caregiver concerns that their only role in the patient's illness is supportive. Caregiver assessments should include questions relating to their ability to provide adequate care to the patient and also to self-care. ${ }^{\text {el } 11}$ Assistance with providing care may include home safety evaluations, information regarding the illness, understanding the role of medications, and knowing who to contact and how to handle complications or emergencies including backup plans for caregiver incapacity. The following are example questions neurologists can use to assess caregiver well-being: Are you feeling overwhelmed? How is your health? What are you doing to take care of yourself? Do you feel isolated? Do you have time to meet your financial, work, parental, or other obligations? With these simple questions, neurologists can provide caregivers with important validation and may be able to address issues directly or refer caregivers for further counseling or other necessary support (e.g., respite or home health services).

APPROPRIATE REFERRAL FOR SPECIALIZED PALLIATIVE CARE SERVICES AND HOSPICE There are many barriers preventing neurologists from appropriately referring patients to specialized palliative 
care services and hospice. Unsatisfactory prognostic predictors for specific illnesses, fear of diminishing hope in patients, and physicians' lack of fundamental palliative care skills are examples of obstacles that contribute to the underutilization of these services. Limitations of Medicare hospice guidelines for neurologic illnesses (see table) also present a potential obstacle, including being overly conservative for patients with amyotrophic lateral sclerosis and dementia compared with newer empiric criteria ${ }^{\text {el2,el3 }}$ and nonspecific or nonexistent for patients living with PD, MS, and other less common conditions. ${ }^{21}$

Referral to specialist palliative care services are warranted if patients or family members have needs going beyond their physicians' ability to manage and may include the following: end-of-life care, feeding tube discussions or other complex interventions, spiritual concerns, distressing psychological issues, lack of caregiver or need for additional caregiver support, difficult to control physical symptoms, need for capacity assessment or power of attorney disputes, home safety issues, or communication issues within a family. Red flags such as frequent hospital admissions (e.g., pneumonia, falls, and urinary tract infection), unexplained weight loss, dysphagia, restricted activities of daily living, increased somnolence, or a rapid decline in function may signify the need for referral to hospice. Research suggests that patients are referred to hospice too infrequently or too late. Thirty percent of patients with advanced dementia go to hospice, and $25 \%$ of hospice stays are 3 days or less. ${ }^{\text {el4 }}$

The benefits of referral to palliative care services are becoming increasingly well-documented, including in neurologic populations. ${ }^{26} \mathrm{~A}$ well-publicized randomized controlled trial of palliative care vs standard oncology care for 151 patients with metastatic lung cancer found improvements in not only quality of life and depression but also median survival (11.6 vs 8.9 months). ${ }^{13,26}$ Similarly, a well-performed randomized controlled trial of 52 patients with advanced MS showed that outpatient palliative care improved caregiver burden and reduced the cost of care, including less inpatient care. ${ }^{\mathrm{e} 15}$

WHAT RESOURCES ARE NEEDED TO SET UP A PALLIATIVE CARE TEAM IN MY PRACTICE? The following is an outline of resources needed to set up a palliative care team in a neurology practice and is based on the University of Colorado Hospital Outpatient Neurology Supportive \& Palliative Care Clinic and the University of Toronto Palliative Program for Parkinson Disease and Related Disorders. Part of our impetus for setting up these clinics was the need for an interdisciplinary team to adequately address the full breadth of palliative care issues facing our patients. Ideally, a palliative care team should consist of a physician, social worker, and counselor with some spiritual training. Notably, spiritual support services are associated with higher quality of life across multiple studies $^{\mathrm{e} 16}$; however, having spiritual support from the community, but not from a medical team, may be associated with more aggressive treatment. ${ }^{\text {e17 }}$

More important than the specific makeup of the team is the commitment of its members. The University of Toronto team includes a neurologist, palliative care physician, and a spiritual advisor, whereas the University of Colorado Hospital team includes a neurologist, a nurse with prior hospice experience, a social worker, a chaplain, and an acupuncturist. We strongly encourage all team members to pursue palliative-specific readings and workshops if they do not have a background in this area. ${ }^{10}$ The American Academy of Neurology and many subspecialty meetings now have neurology-specific palliative care offerings.

The logistics of palliative care may differ from standard patient visits. Our initial visits may last more than 2 hours, and we encourage family members and informal caregivers to attend palliative care appointments. Both clinics were started with volunteer help and are partially dependent on philanthropy to maintain their full operation. Local disease-specific organizations may be interested in providing social work or other support for clinics. We find that on-site and integrated consultations do make a difference regarding both access and quality of care.

RESEARCH AND EDUCATIONAL PRIORITIES Interest in palliative care within the neurologic community is increasing, but there are several research gaps that need to be addressed, including:

1. Development and validation of more accurate prognostic predictors, particularly for 6-month survival to alert physicians for potentially appropriate hospice referrals.

2. Better identification of high-risk patients and caregivers for palliative care referrals.

3. Clinical trials including implementation studies to improve management of nonmotor symptoms.

4. Patient-centered studies to identify and characterize palliative care needs in neurology and patient preferences for addressing these needs.

5. Cost-effectiveness and outcome studies of palliative care interventions.

Despite recent efforts to improve the palliative care training of neurology resident physicians, only $52 \%$ of programs offer a didactic experience in endof-life and/or palliative care, and less than $8 \%$ provide a clinical rotation. ${ }^{3}$ These data support the continuing need for enhanced palliative care training of neurology resident physicians. Neurologists and primary 
care physicians may benefit from further training regarding primary palliative care skills through meetings, journals, and other continuing medical education opportunities. Palliative care teams may also need specialized training for managing neurology patients. Finally, patients and caregivers need more/better information about palliative care and hospice and may benefit from talks given in the community and online resources.

\section{AUTHOR CONTRIBUTIONS}

I.B.: writing of the first draft and revision of subsequent drafts. J.M.: assistance with conceptualization of the manuscript and revision of subsequent drafts. J.K.: assistance with response to reviewers and final revision. B.K.: design and conceptualization of the manuscript.

\section{STUDY FUNDING}

Supported by the NIH (1 K07 Ag030337-01A2), Veterans Administration Medical Center-Colorado Research to Improve Care Coordination (CRICC) Pilot Grant Program, and the University of Colorado Hospital Clinical Effectiveness and Patient Safety Program.

\section{DISCLOSURE}

The authors report no disclosures relevant to the manuscript. Go to Neurology.org for full disclosures.

Received January 31, 2014. Accepted in final form April 27, 2014.

\section{REFERENCES}

1. Palliative care in neurology. The American Academy of Neurology Ethics and Humanities Subcommittee. Neurology 1996;46:870-872.

2. Accreditation Council for Graduate Medical Education. Neurology program requirements. Available at: http:// www.acgme.org. Accessed December 11, 2013.

3. Creutzfeldt CJ, Gooley T, Walker M. Are neurology residents prepared to deal with dying patients? Arch Neurol 2009;66:1427-1428.

4. Chahine LM, Malik B, Davis M. Palliative care needs of patients with neurologic or neurosurgical conditions. Eur J Neurol 2008;15:1265-1272.

5. Howlett JG. Palliative care in heart failure: addressing the largest care gap. Curr Opin Cardiol 2011;26:144-148.

6. Heigener DF, Rabe KF. Palliative care concepts in respiratory disease. Respiration 2011;82:483-491.

7. Hussain JA, Russon L. Supportive and palliative care for people with end-stage renal disease. Br J Hosp Med 2012; 73:640-644.

8. Hussain J, Adams D, Campbell C. End-of-life care in neurodegenerative conditions: outcomes of a specialist palliative neurology service. Int J Palliat Nurs 2013;19:162-169.

9. Foley KM, Carver AC. Palliative care in neurology. Neurol Clin 2001;19:789-799.

10. Voltz R, Bernat JL, Borasio GD, Maddocks I, Oliver D, Portenoy RK. Palliative Care in Neurology. Oxford, UK: Oxford University Press; 2004.

11. Strand JJ, Kamdar MM, Carey EC. Top 10 things palliative care clinicians wished everyone knew about palliative care. Mayo Clin Proc 2013;88:859-865.

12. Jablonski A. Palliative care: misconceptions that limit access for patients with chronic renal disease. Semin Dial 2008;21:206-209.
13. Temel JS, Greer JA, Muzikansky A, et al. Early palliative care for patients with metastatic non-small-cell lung cancer. N Engl J Med 2010;363:733-742.

14. Bunting-Perry LK. Palliative care in Parkinson's disease: implications for neuroscience nursing. J Neurosci Nurs 2006;38:106-113.

15. World Health Organization. Definition of palliative care. Available at: http://www.who.int/cancer/palliative/definition/ en/. Accessed December 11, 2013.

16. Bernat JL. Ethical and legal issues in palliative care. Neurol Clin 2001;19:969-987.

17. Center to Advance Palliative Care. Defining palliative care. Available at: http://www.capc.org/building-a-hospitalbased-palliative-care-program/case/definingpc. Accessed March 14, 2014.

18. Bekelman DB, Nowels CT, Retrum JH, et al. Giving voice to patients' and family caregivers' needs in chronic heart failure: implications for palliative care programs. J Palliat Med 2011;14:1317-1324.

19. Bunting-Perry LK. Palliative care in Parkinson's disease: implications for neuroscience nursing. J Neurosci Nurs 2006;38:106-113.

20. Vogel SL. What physicians should know about hospice. Ochsner J 2011;11:353-356.

21. U.S. Department of Health and Human Services Health Care Financing. Medicare Hospice Benefits [online]. Available at: http://www.medicare.gov/Publications/Pubs/ pdf/02154.pdf. Accessed April 9, 2014.

22. Lanoix M. Palliative care and Parkinson's disease: managing the chronic-palliative interface. Chronic Illn 2009;5: 46-55.

23. Hudson PL, Aranda S, Kristjanson LJ. Meeting the supportive needs of family caregivers in palliative care: challenges for health professionals. J Palliat Med 2004; 7:19-25.

24. Hoyert DL, Xu JQ. Deaths: Preliminary Data for 2011. National Vital Statistics Reports, vol. 61, no. 6. Hyattsville, MD: National Center for Health Statistics; 2012.

25. Martinez-Martin P, Schapira AH, Stocchi F, et al. Prevalence of nonmotor symptoms in Parkinson's disease in an international setting: study using nonmotor symptoms questionnaire in 545 patients. Mov Disord 2007;22: 1623-1629.

26. Miyasaki JM, Long J, Mancini D, et al. Palliative care for advanced Parkinson disease: an interdisciplinary clinic and new scale, the ESAS-PD. Parkinsonism Relat Disord 2012;18(suppl 3):S6-S9.

27. Kim Y, Schulz R. Family caregivers' strains: comparative analysis of cancer caregiving with dementia, diabetes, and frail elderly caregiving. J Aging Health 2008;20:483-503.

28. Sleeman KE, Ho YK, Verne J, et al. Place of death, and its relation with underlying cause of death, in Parkinson's disease, motor neurone disease, and multiple sclerosis: a population-based study. Palliat Med 2013;27:840-846.

29. Snell K, Pennington S, Lee M, Walker R. The place of death in Parkinson's disease. Age Ageing 2009;38: 617-619.

30. Gomes B, Calanzani N, Gysels M, Hall S, Higginson IJ. Heterogeneity and changes in preferences for dying at home: a systematic review. BMC Palliat Care 2013;12:7.

31. Tuck KK, Brod L, Nutt J, Fromme EK. Preferences of patients with Parkinson's disease for communication about advanced care planning. Am J Hosp Palliat Care Epub 2013 Sep 19. 
32. Mitchell SL, Kiely DK, Hamel MB. Dying with advanced dementia in the nursing home. Arch Intern Med 2004; 164:321-326.

33. Ahronheim JC, Mulvihill M, Sieger C, Park P, Fries BE. State practice variations in the use of tube feeding for nursing home residents with severe cognitive impairment. J Am Geriatr Soc 2001;49:148-152.

34. Maass A, Reichmann H. Sleep and non-motor symptoms in Parkinson's disease. J Neural Transm 2013;120:565-569.

35. Attarian H. Importance of sleep in the quality of life of multiple sclerosis patients: a long under-recognized issue. Sleep Med 2009;10:7-8.

36. Inelmen EM, Mosele M, Sergi G, Toffanello ED, Coin A, Manzato E. Chronic pain in the elderly with advanced dementia: are we doing our best for their suffering? Aging Clin Exp Res 2012;24:207-212.

37. Manu E, Marks A, Berkman CS, Mullan P, Montagnini M, Vitale CA. Self-perceived competence among medical residents in skills needed to care for patients with advanced dementia versus metastatic cancer. J Cancer Educ 2012;27:515-520.

38. Turner-Stokes L, Sykes N, Silber E, Khatri A, Sutton L, Young E. From diagnosis to death: exploring the interface between neurology, rehabilitation and palliative care in managing people with long-term neurological conditions. Clin Med 2007;7:129-136.

39. Teno JM, Weitzen S, Fennell ML, Mor V. Dying trajectory in the last year of life: does cancer trajectory fit other diseases? J Palliat Med 2001;4:457-464.

40. Clarke DM, McLeod JE, Smith GC, Trauer T, Kissane DW. A comparison of psychosocial and physical functioning in patients with motor neurone disease and metastatic cancer. J Palliat Care 2005;21:173-179.

41. Schubart JR, Kinzie MB, Farace E. Caring for the brain tumor patient: family caregiver burden and unmet needs. Neuro Oncol 2008;10:61-72.

42. Phillips W, Shannon KM, Barker RA. The current clinical management of Huntington's disease. Mov Disord 2008; 23:1491-1504.

43. Dawson S, Kristjanson LJ, Toye CM, Flett P. Living with Huntington's disease: need for supportive care. Nurs Health Sci 2004;6:123-130.

44. Figved N, Myhr KM, Larsen JP, Aarsland D. Caregiver burden in multiple sclerosis: the impact of neuropsychiatric symptoms. J Neurol Neurosurg Psychiatr 2007;78:1097-1102.

45. Rabkin JG, Wagner GJ, Del Bene M. Resilience and distress among amyotrophic lateral sclerosis patients and caregivers. Psychosom Med 2000;62:271-279.

46. Riedel O, Klotsche J, Spottke A, et al. Frequency of dementia, depression, and other neuropsychiatric symptoms in
1,449 outpatients with Parkinson's disease. J Neurol 2010;257:1073-1082.

47. Clipp EC, George LK. Dementia and cancer: a comparison of spouse caregivers. Gerontologist 1993;33:534-541.

48. Schulz R, Boerner K, Shear K, Zhang S, Gitlin LN. Predictors of complicated grief among dementia caregivers: a prospective study of bereavement. Am J Geriatr Psychiatry 2006; 14:650-658.

49. Goodlin SJ. Palliative care in congestive heart failure. J Am Coll Cardiol 2009;54:386-396.

50. O'Brien MR, Whitehead B, Jack BA, Mitchell JD. From symptom onset to a diagnosis of amyotrophic lateral sclerosis/motor neuron disease (ALS/MND): experiences of people with ALS/MND and family carers-a qualitative study. Amyotroph Lateral Scler 2011;12:97-104.

51. Aoun SM, Connors SL, Priddis L, Breen LJ, Colyer S. Motor neurone disease family carers' experiences of caring, palliative care and bereavement: an exploratory qualitative study. Palliat Med 2012;26:842-850.

52. Baile WF, Buckman R, Lenzi R, Glober G, Beale EA, Kudelka AP. SPIKES: a six-step protocol for delivering bad news-application to the patient with cancer. Oncologist 2000;5:302-311.

53. VITAL talk. Available at: http://www.vitaltalk.org. Accessed March 18, 2014.

54. Cheon SM, Ha MS, Park MJ, Kim JW. Nonmotor symptoms of Parkinson's disease: prevalence and awareness of patients and families. Parkinsonism Relat Disord 2008;14: 286-290.

55. Fruehwald S, Loeffler-Stastka H, Eher R, Saletu B, Baumhackl U. Depression and quality of life in multiple sclerosis. Acta Neurol Scand 2001;104:257-261.

56. Simmons Z, Bremer BA, Robbins RA, Walsh SM, Fischer S. Quality of life in ALS depends on factors other than strength and physical function. Neurology 2000;55: 388-392.

57. Chaudhuri KR, Healy DG, Schapira AH; National Institute for Clinical Excellence. Non-motor symptoms of Parkinson's disease: diagnosis and management. Lancet Neurol 2006;5:235-245.

58. Chen JJ, Marsh L. Depression in Parkinson's disease: identification and management. Pharmacotherapy 2013;33: 972-983.

59. Lemke MR, Fuchs G, Gemende I, et al. Depression and Parkinson's disease. J Neurol 2004;251(suppl 6): $\mathrm{VI} / 24-\mathrm{VI} / 27$.

60. Heyland DK, Barwich D, Pichora D, et al. Failure to engage hospitalized elderly patients and their families in advance care planning. JAMA Intern Med 2013;173: 778-787. 